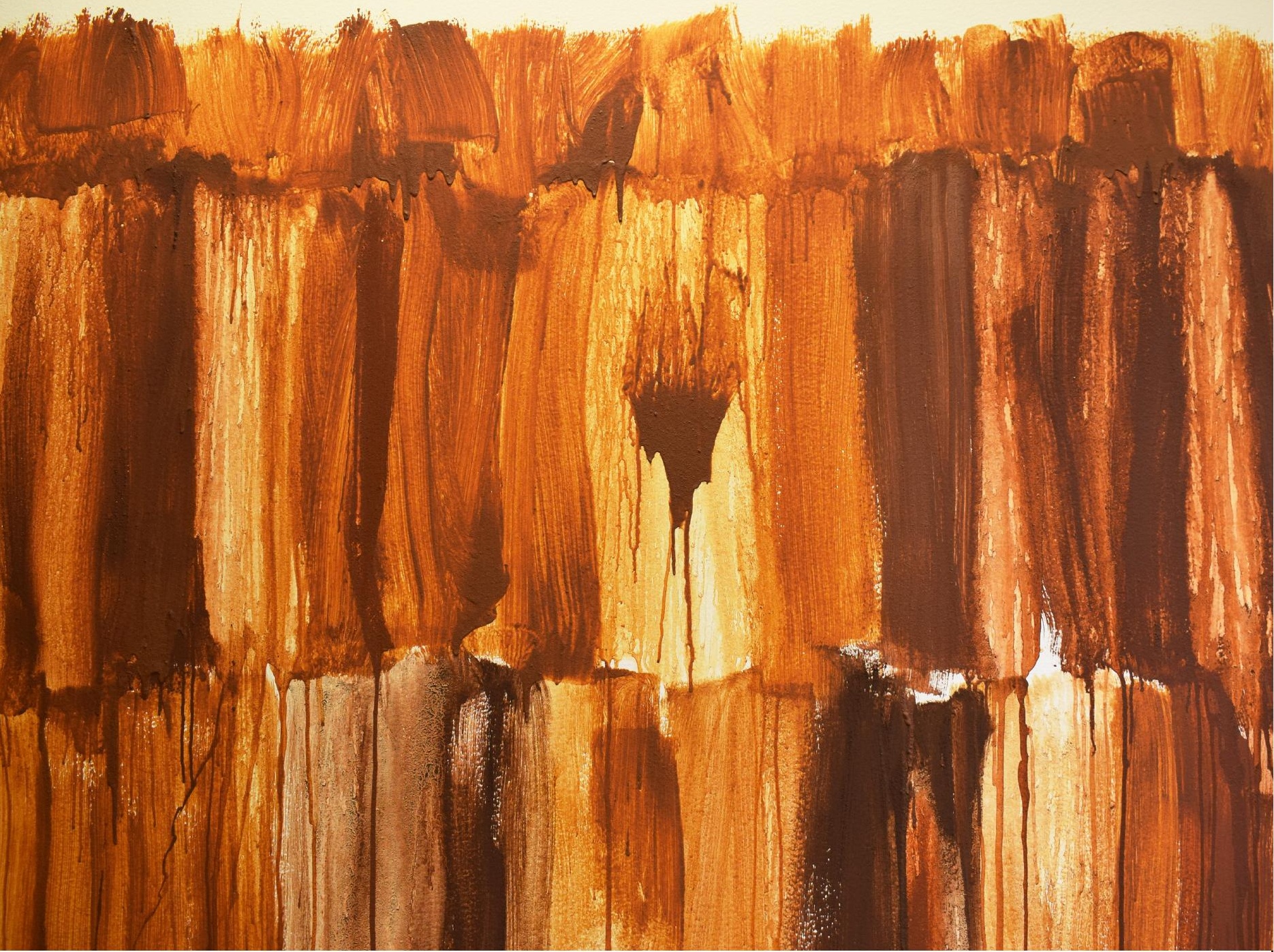

ARIEL FERREIRA. ATÉ AQUI, 2019.

INSTALAÇÃO SITE SPECIFIC, PINTURA COM TINTA DE TERRA E ROCHAS,

MEMORIAL MINAS GERAIS VALE, PRAÇA DA LIBERDADE, BELO HORIZONTE.

FOTOGRAFIA: ARIEL FERREIRA. 


\section{A CONSTRUÇÃO DA PAISAGEM E AS EXPULSÕES EM NOVA IORQUE SOB A ÉGIDE DA MUDANÇA CLIMÁTICA}

MARINA VALE VIEGAS:

RESUMO A proximidade com a água caracterizou o surgimento de grande parte dos assentamentos que viriam a se tornar cidades. Hoje, a paisagem nova-iorquina corre o risco de ser atingida - e destruída - em decorrência das mudanças climáticas. Desde a falta de água, o aumento dos níveis dos mares e o advento de furacões, como é o caso do Sandy, que se estendeu pela costa leste dos Estados Unidos, os desastres naturais tornaram-se cada vez mais frequentes. Estes são responsáveis pelas expulsões nas microlocalidades da cidade e evidenciam a necessidade de novos processos de planejamento urbano que agreguem espaço, práticas sociais e viabilidade tecnológica e orçamentária. Os aspectos dos participatory designs, como - The Big $U$, podem apresentar soluções.

PALAVRAS-CHAVE paisagem, expulsões, Furacão Sandy.

\section{THE CONSTRUCTION OF THE LANDSCAPE AND THE EXPULSIONS IN NEW YORK UNDER CLIMATE CHANGE}

ABSTRACT The proximity to the water characterizes the emergence of settlements which would become cities. Today, New York's landscape runs the risk of being hit - and destroyed - because of climate changes. From the lack of water, to the rise of sea levels, and the advent of hurricanes, such as Sandy which extended through out Unites State's east coast, natural disasters became increasingly more frequent. Those are responsible for the expulsions in the micro localities of the city and they put in evidence the necessity of new processes of urban planning that combine space, social practices and technological and budgetary viability. The aspects of participatory projects like The Big $U$ may present solutions.

KEYWORDS landscape, expulsions, Hurricane Sandy.

* Universidade Federal de Minas Gerais (UFMG). 


\section{Introdução}

água configura um fator determinante a um assentamento: além de ser uma
necessidade humana básica, ela guia a formação de cidades e, por meio dos rios, realiza o transporte de mercadorias. Entretanto, "na era moderna, os limites aquáticos das cidades começaram a mudar de significado, tornando-se pontos de interesse estético" (SENNETT, 20I8, p. 303). Hoje, as cidades cercadas por água correm o risco de serem inundadas, ao mesmo tempo que a impermeabilização do solo resulta na não retenção de mais do que I5\% da água da chuva. Além disso, a escassez de água apresenta um sério problema para as gerações futuras. Sennett (20I8) relata que, segundo o projeto Observação da Terra da NASA, as “tempestades episódicas” acontecerão com maior frequência devido ao aquecimento dos oceanos.

A degradação da biosfera pelo homem, desde o século ı8, diz respeito à busca incessante pela produção do excedente que caracteriza o sistema capitalista. As novas tecnologias e o alcance dos mercados possibilitam que a produção capitalista do espaço se materialize em uma escala geográfica inimaginável, o que gera consequências sociais em diferentes níveis. Enquanto os detentores do capital ascendem e veem suas riquezas crescerem, as camadas menos afortunadas ficam cada vez mais à deriva. Nesse sentido, Sassen (2016) argumenta que a economia global é responsável por expulsões que ocorrem com indivíduos e a própria biosfera. Estas são causadas, agudas e brutais:

Nas duas últimas décadas, houve grande crescimento da quantidade de pessoas, empresas e lugares expulsos das ordens sociais e econômicas centrais de nosso tempo. Essa guinada em direção à expulsão radical foi possibilitada por decisões elementares em alguns casos; em outros, por algumas de nossas conquistas econômicas e técnicas mais avançadas. O conceito de expulsão leva-nos além daquela ideia que nos é mais familiar da desigualdade crescente como forma de entender as patologias do capitalismo global atual (SASSEN, 2018, p. 9). 
A produção capitalista do espaço tem como prioridade o lucro, e muitas vezes ela resulta na expulsão. Ou seja, o planejamento urbano adota caraterísticas do mercado, e as parcerias público-privadas viabilizam muitas obras que não poderiam ser financiadas pelo Estado (HARVEY, 2005). A própria urbanização determina, segundo David Harvey (2005, p. I68-I69), “um processo social especialmente fundamentado, no qual um amplo leque de atores, com objetivos e compromissos diversos, interagem por meio de uma configuração específica de práticas sociais entrelaçadas". As cidades ou as consideradas megacidades, como Nova Iorque, vivenciam as relações entre os seus moradores de forma a materializar o crescimento de alguns em contrapartida ao deslocamento de vários outros. Ademais, há um terceiro fator que perturba, mesmo que de maneiras diferentes, todas as camadas sociais: a natureza.

A relação entre o usuário e o espaço abrange a categoria da paisagem. No caso nova-iorquino, principalmente, a paisagem configura um mecanismo da economia simbólica: os símbolos fazem parte do cotidiano e da imagem da cidade, aqui entendida como espaço de consumo ou destino turístico (ZUKIN, I995). O conceito de paisagem definido por Georg Simmel (2013) determina uma construção social, a qual é condicionada para a arte e pela cultura. Além disso, para Simmel, a categoria da paisagem permite que conceitos se cruzem de diversas maneiras nas mentes dos indivíduos, e eles são os próprios autores das imagens. Entender como o frequentador percebe o espaço das cidades faz-se essencial para compreender como as transformações na paisagem alteram a vida de seus usuários. Dessa maneira, a manutenção da paisagem facilita para que haja a conexão e o sentimento de pertencimento dos moradores com o lugar (SIMMEL, 2013).

Em 20I2, o Furacão Sandy soou um alerta para a cidade de Nova Iorque: a água provou o seu poder de destruição. O aumento dos níveis do mar configura um grande problema para o sul da ilha, principalmente (SORKIN, 20I8). Os órgãos públicos precisam se planejar para a fortificação da malha urbana no caso da invasão do mar que já é expectada. Projetos para a acomodação da água estão em andamento, mas nenhuma medida drástica foi tomada até o momento (SENNETT, 20I8). As soluções de escoamento da água não são a única saída. Como argumenta Sorkin (2018, p. 50, tradução nossa): "Um edifício é a fonte de cerca de $75 \%$ da emissão de gases do efeito estufa em Nova Iorque”. Portanto, este é um problema que também diz respeito à indústria

1 As building is the source of about 75 percent of greenhouse emissions in New York. 
imobiliária e ao planejamento urbano da cidade. Entretanto, a cultura construtiva na cidade caminha em direção oposta à preocupação do autor.

As entidades públicas e privadas, dotadas ou não de capital de investimento, têm sido alarmadas pelos desastres que afetam a vida cotidiana dos moradores das cidades. Como consequência das ações do homem, as catástrofes naturais devem ser discutidas por todos: geógrafos, urbanistas, usuários das cidades, investidores, entre outros. Desta maneira, a partir de conceitos que abrangem as urbanizações e transformações sociais decorrentes dos desastres, pretende-se analisar como a escolha de local para o assentamento que viria a se tornar Nova Iorque hoje apresenta riscos para a cidade. A geografia que facilitou o acesso e o comércio entre a costa leste norte-americana e a Europa agora cria uma situação de vulnerabilidade em relação ao mar.

Portanto, o objeto de estudo consiste na manutenção, construção e adaptação da paisagem em Nova Iorque sob a égide da presente expulsão de moradores de microlocalidades, resultado de desastres naturais, como o Furacão Sandy. Os objetivos deste artigo consistem em: descrever o processo de urbanização e as principais transformações na paisagem do sul da ilha de Manhattan, sobretudo; avaliar os impactos espaciais, sociais e paisagísticos do Furacão Sandy; identificar as maiores consequências sofridas pelas diferentes camadas sociais; discutir soluções imediatas e duradouras para as cidades; e analisar o projeto de participatory design, o The Big U. Os pressupostos acerca do tema são: o desastre ambiental evidencia e propicia a exposição, além de causar a expulsão dos moradores locais em situações verificadas nos seus respectivos territórios de trabalho e moradia, principalmente, e eles têm sido condicionados e mitigados de diferentes maneiras; o despreparo dos setores públicos para responder de maneira rápida e eficiente a um acidente natural muitas vezes esperado - esse quadro significa também a falta de métodos de planejamento urbano que consideram a multidisciplinaridade e as peculiaridades que englobam uma unidade de vizinhança e de representação social e política pautadas nas microlocalidades; a contradição entre a produção capitalista do espaço e a força da natureza que comprova a necessidade de uma nova postura, definições e processos assinalados nas realidades urbanas para se conceber e produzir o espaço.

A metodologia adotada neste artigo abrange aspectos qualitativos, descritivos e do estudo de caso, uma vez que se considera uma microlocalidade e questões referentes 
ao meio ambiente. Esses aspectos possibilitam o entendimento e a análise detalhada da situação e de suas articulaç̃os com os princípios que engendram mais recentemente o planejamento e a produção da paisagem, e suas peculiaridades. Além desta introdução e das considerações finais, este artigo divide-se em três outras partes: a primeira dedica-se aos processos de urbanização que Nova Iorque experienciou com o objetivo de situar o planejamento urbano nas transformações latentes que conformam a característica de constante substituição na paisagem da cidade, e também às inadequações da construção civil em relação à manutenção do meio ambiente. A segunda discorre sobre o Furacão Sandy, ocorrido em 20I2, e os seus impactos espaciais, sociais e paisagísticos. A terceira analisa o The Big $U$, um projeto que adota os modelos de parceria público-privada e de participatory design - conforme definido por seus idealizadores.

\section{A construção da paisagem nova-iorquina}

A geografia da cidade de Nova Iorque era a sua vantagem suprema. Ela superava Filadélfia como o principal porto da nação não em razão da superioridade dos seus moradores, mas devido a superioridade da sua baía e o acesso ininterrupto do norte do rio Hudson às terras de agricultura abundante ao oeste. A posição da cidade era uma benção ocasionalmente mencionada nos sermões ou discursos patriotas, mas havia pouco conhecimento acerca da geologia ou do processo que levou à formação do aparentemente sólido e imóvel material sobre o qual as ruas da cidade e edifícios eram construídos. Nem mesmo existia muita inclinação para a explicação de como ou porque a planície costeira onde Nova Iorque está localizada tinha surgido do mar. [...] Traços do passado de Nova Iorque estão enterrados, escondidos e precisam ser decifrados ${ }^{2}$ (HOMBERGER, I998, p. ı०, tradução nossa).

A cidade de Nova Iorque é resultado de um processo de urbanização histórico que ocorre na sua malha urbana desde o século I7. Entre i61o e i664, famílias protestantes holandesas habitaram a Nova Amsterdã, o primeiro assentamento permanente no espaço que, atualmente, situa-se Nova Iorque (HOMBERGER, I998). A ocupação aconteceu principalmente no sul da ilha de Manhattan, onde está localizado, hoje, o Financial District. O maior problema encontrado pelos estrangeiros foi a condição de vida primitiva dos povos originários (HOMBERGER, I998). A Wall Street foi inicialmente uma barricada que os novos moradores construíram para sua defesa, uma vez que, na época, os ataques eram frequentes.
2 The geography of New York City was the city's supreme advantage. Is surpassed Philadelphia as the nation's principal port not because of the superiority of its people, but due to the superiority of its harbour, and its unimpeded access up the Hudson River to the rich agricultural lands to the west. The city's natural setting was a blessing occasionally mentioned in a sermon or patriotic dress but there was little knowledge of geology or of the process which had led to the formation of the seemingly solid and immovable material upon which the city's streets and buildings were built. Nor was there much inclination to explain how or why the coastal plain upon which New York was located had emerged from the sea. [...] Traces of the past in New York are buried, hidden, and need deciphering. 
Quando os ingleses tomaram o controle de Nova Iorque, o assentamento havia se desenvolvido e era habitado por advogados, negociantes e oficiais do governo. As ruas, ao sul da ilha, recebiam lojas de café, tavernas, e clubes para membros. Por exemplo, a Fraunces Tavern, ainda operante, data dessa época. As ruas estavam sempre movimentadas e registraram inúmeros conflitos entre ingleses e holandeses. No final do século I8, todas as ruas de onde, atualmente, está localizado o Financial District estavam desenhadas na malha urbana; a maioria permanece até hoje (HOMBERGER, I998). Para além de criar imagens que fazem parte do imaginário popular, a construção da paisagem ao longo dos séculos conta a história da cidade. Augustin Berque (I988, p. 84) explica:

A paisagem é uma marca, pois expressa uma civilização, mas é também uma matriz porque participa dos esquemas de percepção, de concepção e de ação - ou seja, da cultura - que canalizam, em um certo sentido, a relação de uma sociedade com o espaço e com a natureza.

Ademais, no caso de cidades predominantemente verticalizadas, a paisagem é composta por marcos que orientam o pedestre e que são importantes na descrição do espaço, como é frequente na literatura e nos filmes. Em Nova Iorque, existem diversos marcos que simbolizam a sua história. A representação do tempo a partir da proteção da paisagem, ou seja, a imagem da cidade inalterada, pode ser compreendida através de dois conceitos: a temporalidade e a temporaneidade. A primeira garante que o passado seja levado ao futuro, através da proteção da paisagem; a segunda, por ser limitada ao presente, prova que o congelamento de uma imagem não está suscetível às mudanças intrínsecas à paisagem real, ou seja, a paisagem deve ser entendida como uma temporalidade dentro de uma temporaneidade (ASSUNTO, 20I3). A paisagem é justamente a imagem do tempo, uma vez que ela captura a espacialização temporal e está carregada de signos. Portanto, criar uma paisagem significa ter consciência espacial do lugar.

No século 20, Robert Moses (I888-I98I) ficou conhecido como o master builder da área metropolitana de Nova Iorque por ter sugerido transformações que mudariam drasticamente a sua paisagem. O engenheiro detinha poder como nenhum outro oficial público, e nada na cidade era construído sem o seu aval. Ele propôs projetos contraditórios, dentre eles, o Brooklyn-Battery Crossing. Ele desejava solucionar os 
engarrafamentos resultantes do alto volume de veículos que transitavam entre os dois boroughs - Manhattan e Brooklyn. O projeto da ponte que ligaria o Battery Park ao Brooklyn levava em consideração a destruição de grande parte do parque, da Wall Street e do sul de Manhattan (CARO, I975). O principal problema apontado pelos seus opositores foi a interferência na paisagem da ilha. Moses respondeu que faria uma estrutura leve, mas as renderizações não agradaram ao então Presidente do Borough de Manhattan, Stanley Isaacs (CARO, I975). Além disso, o mercado imobiliário alertou que a construção de uma ponte ao longo do Battery Park que impedisse a iluminação e a ventilação naturais desvalorizaria o valor de uso e de venda do solo do seu entorno.

Como o mercado imobiliário no sul de Manhattan é há décadas um dos mais lucrativos do mundo e, ao mesmo tempo, uma das principais fontes de renda do governo da cidade, o projeto não aconteceu. No seu lugar foi construído o Brooklyn-Battery Tunnel (I950), um túnel subterrâneo. "A importância única do Battery Park para a cidade de Nova Iorque é obviamente não pelo mar, mas pelo ar - de um avião ou de uma plataforma de observação do Empire State Building no céu e a mais de metros acima da ilha de Manhattan"3 (CARO, I975, p. 647, tradução nossa). A paisagem e a relação que os moradores têm com a cidade, nesse caso, salvaram o parque e o sul da ilha - além da ponte que seria gravemente atingida pelo Furacão Sandy, conforme será discutido.

Por outro lado, a construção civil também configura um desafio para a manutenção das cidades como um todo: o caráter poluente das obras - e a falta de tecnologia que possibilite solucionar ecológico e financeiramente esse problema - responsabiliza-se em parte pelos desastres naturais que acontecem no mundo. Assim como Michael Sorkin (20I8) afirma, o ar de Nova Iorque custa caro: não só para os investidores, mas também à natureza. Entretanto, a cultura construtiva enraíza-se de tal forma que existem poucos incentivos a estudos a favor do meio ambiente, uma vez que as empresas ligadas à produção de cimento se beneficiam, junto aos governos, da sua venda. Contudo:

Uma meta de no máximo dois graus de aquecimento global foi estabelecida para as próximas décadas pelo Painel Intergovernamental sobre Mudanças Climáticas (IPCC, na sigla inglesa); mas ela com certeza não será alcançada. Pra alcançá-la, o cimento - cuja fabricação é extremamente poluente - não deveria mais ser um material de construção onipresente, mas atualmente não há disponibilidade de materiais alternativos baratos (SENNETT, 2018, p. 302).
3 The unique importance of Battery Park to New York City was obvious not from the sea but from the air - from a plane or from the observation platform of the Empire State Building a thousand feet in the sky over the Manhattan Island. 
Segundo estudos realizados pela CarbonCure, empresa norte-americana, 8\% da emissão anual de carbono do mundo vem da produção do cimento. O problema decorre da sua fabricação: o aquecimento de calcário e argila à 2.700 graus Fahrenheits realiza-se através da queima de carvão e outros combustíveis fósseis. Além disso, o processo químico gerado por esse aquecimento resulta em pó de cimento e dióxido de carbono gasoso que é liberado na atmosfera. As pesquisas desenvolvidas em torno desse assunto buscam soluções dentro da própria cadeia produtiva: como usar o carbono, no lugar de parte do cimento, na fabricação de concreto. Ao utilizar $\mathrm{CO}_{2}$ líquido no seu preparo, ele se transforma em carbonato de cálcio sólido e auxilia na ligação entre os componentes do concreto. Ou seja, o CO2 fica retido no produto final (BEISER, 2020).

A única dúvida refere-se à quantidade de dióxido de carbono possível de ser utilizado de maneira a não afetar o desempenho do concreto, e a empresa acompanha de perto as obras que utilizam o dióxido de carbono como componente. Até o dia da publicação do artigo de Beiser (2020), 200 empresas que produzem concreto na América do Norte e em Singapura já utilizavam essa técnica que pode ser facilmente construída em qualquer planta de fábrica. Entretanto, a economia de cimento gira em torno de $5 \%$ nesses casos (BEISER, 2020). Outras pesquisas como essa estão em desenvolvimento no mundo. Contudo:

A capacidade que a biosfera tem de renovar terra, água e ar é extraordinária. Porém, está baseada em tempos e ciclos vitais específicos que nossas inovações técnicas, químicas e organizacionais estão rapidamente ultrapassando. As economias industrializadas há muito vêm provocando danos à biosfera. (SASSEN, 20I6, p. I79)

Além da preservação do meio ambiente, a produção capitalista do espaço ultrapassa os limites saudáveis de transformações das ecologias locais que representam a alma das cidades (ZUKIN, 20II). Segundo Jacobs (I992), a luta pela manutenção do que é comum ao cotidiano, como o ballet das calçadas, também significa a conservação das diversidades, da segurança e do contato entre indivíduos nas ruas. Apesar disso, nas palavras de Harvey (2005, p. 5I): “O capital passa a ser representado na forma de uma paisagem física, criada à sua própria imagem, criada com valor de uso, acentuando a acumulação progressiva do capital numa escala expansível”. Desta maneira, a paisagem torna-se, concomitantemente, a expressão do tempo e da produção simbólica no espaço da cidade, ou seja, a história é transformada em mercadoria, assim como a cultura. 
No que diz respeito ao capital acumulado no espaço, a manutenção da paisagem e, portanto, a manutenção do investimento passado se contradiz à ideia de novas construções ou de alterações em função dos eventos climáticos. No caso nova-iorquino, a localização é primordial ao sistema capitalista. O investimento em infraestrutura social e na preservação da vida cotidiana, então, fica em segundo plano, assim como a preocupação com os desastres naturais. Segundo Harvey (2005) relata, a capacidade de produzir o espaço dá direito ao seu domínio. E ao ser irrompido pela água, o mesmo espaço passa a ser dominado pela sua força.

\section{O furacão Sandy}

O Furacão Sandy atingiu Nova Iorque em 29 de outubro de 20I2. Durante 48 horas, ventos, chuva e água destruíram aproximadamente 300 casas, deixaram centenas de milhares de nova-iorquinos sem energia, danificaram infraestruturas públicas e privadas cruciais, e deixaram muitos nova-iorquinos vulneráveis com acesso limitado de comida, água potável, sistema de saúde e outros serviços cruciais. A preparação e resposta imediata da cidade de Nova Iorque ao Furacão Sandy foi uma das maiores mobilizações de serviços públicos na sua história, e demonstraram a dedicação da força de trabalho da cidade e a perseverança dos nova-iorquinos em se recuperar e reconstruir ${ }^{4}$ (CITY OF NEW YORK, 2020, tradução nossa).

Em junho de 20I2, nos Estados Unidos, foram quebrados 3.2I5 recordes de calor (SASSEN, 20I8). Após o Furacão Sandy, nas áreas de habitação social da cidade, 400 edifícios foram danificados e I5.000 residências ficaram mais de duas semanas sem água, energia e aquecimento (SORKIN, 20I8). A falta de equidade ressalta-se pelos desastres antropogênicos mesmo que em um primeiro momento aparente que todos estão no mesmo barco. Os mais de Ioo quilômetros de orla são habitados por moradores do East Village que, predominantemente, configuram uma população de baixo capital cultural e financeiro, pelo Tribeca e Financial District que englobam a classe dos business men da cidade, além dos artistas boêmios do West Village (VIEGAS, 2020). A maneira como se constrói, como se apropria do espaço e como estes moradores habitam Nova Iorque também diz respeito à dialética entre a proteção e o abandono das arquiteturas em caso de desastres, como o Sandy (SENNETT, 20I8). Os que possuem
4 Hurricane Sandy hit New York City on October 29th, 2012. Over the course of 48 hours, wind, rain, and water destroyed approximately 300 homes, left hundreds of thousands of New Yorkers without power, damaged critical public and private infrastructure, and left many New Yorkers vulnerable with limited access to food, drinking water, healthcare, and other critical services. The City of New York's preparation and immediate response to Hurricane Sandy was one of the largest mobilizations of public services in its history, and demonstrated the dedication of the City's workforce and the perseverance of New Yorkers to recover and rebuild. 
5 The problem of the megastructure is not its extent but its subversion of choice and the cruelties

it visits on fragile but indispensable social and spatial ecologies.

capital para recuperar os estragos o fazem, enquanto os outros anseiam pela ajuda das entidades públicas. O que afeta todos de maneira meramente parecida, como a mobilidade, ganha atenção especial em relação às habitações sociais, por exemplo.

Nos Estados Unidos, a proteção pública contra inundação atende os moradores desde que regras de segurança sejam seguidas durante a construção. Contudo, um grande número de prefeituras, instituições responsáveis pelo cumprimento da legislação, sequer avalia esses quesitos ao aprovar projetos nas cidades. Foram identificados II2.480 casos irregulares no país e o orçamento de casos em que o governo já foi acionado ultrapassa um bilhão de dólares. A desocupação dessas casas muitas vezes é impedida em razão da falta de destino dos moradores, além de que essas construções tornam-se impossíveis de serem vendidas pelos proprietários, que pagam valores mais altos de impostos em decorrência do risco adicional (FLAVELLE; SCHWARTZ, 2020).

Para Sennett (20I8), existem duas maneiras de lidar com as consequências do

6 Almost two weeks after Hurricane Sandy struck New York, my wife and I got our heat and hot water back; electric power had returned a few days earlier. Our apartment in Lower Manhattan relies on the Con Edison steam system, not a boiler, and the utility's slow repair process was the source of the lag between the restoration of power and the return of heat. In both cases, though, we had relied on a centralized technology, rather than a distributed one, begging fundamental questions about how we most usually conceptualize and deploy necessary infrastructure. As we rebuilt, we must be alert to the susceptibility of massive systems to massive failure. aquecimento global: atenuação e adaptação. A primeira diz respeito às causas: busca-se, neste caso, a proteção contra os traumas. As bermas funcionam como barreiras de impedimento da entrada de água, por exemplo. Por outro lado, a segunda trabalha com o choque sofrido, ou seja, atenuando a sua força. Para Sennett, ambas deveriam ser projetadas e implementadas em situações de risco. Entretanto, a falta de capital público dificulta a realização dessas medidas de seguranças. As cidades hoje operam como empresas, o que se torna prejudicial na dinâmica socioespacial dos menos afortunados. Segundo Sorkin (2013, p. I92, tradução nossa), “o problema com a megaestrutura não é a sua escala, mas a sua escolha de subversão e as crueldades que visitam as frágeis, mas indispensáveis, ecologias espaciais e sociais" 5. O crítico da arquitetura e morador de Nova Iorque relata a sua experiência:

Quase duas semanas após Nova Iorque ter sido atingida pelo Furacão Sandy, minha mulher e eu tivemos a nossa calefação e água quente de volta; eletricidade tinha voltado alguns dias antes. O nosso apartamento em Lower Manhattan depende do sistema de energia da Com Edison, não um aquecedor boiler, e o lento processo de conserto da utilidade foi uma fonte de defasagem entre a restauração da eletricidade e o retorno da calefação. Nos dois casos, apesar disso, nós dependíamos de uma tecnologia centralizada, ao invés de uma distribuída, o que indaga questões fundamentais sobre como nós geralmente idealizamos e implantamos as infraestruturas necessárias. Enquanto nós reconstruímos, nós devemos ficar alertas à suscetibilidade de sistemas em massa à falhas em massa ${ }^{6}$ (SORKIN, 20I8, p. 46, tradução nossa). 
Ao longo dos anos que sucederam à destruição causada pelo Furacão Sandy, foram debatidas soluções que protegessem a cidade no caso dos futuros problemas causados pela força da água. Em 20I9, a única proposta implementada consistia em sacos de areia que contornam a orla. Contudo, a região ao sul da Wall Street e o South Street Seaport não fazem parte da área de proteção. Essa região contém mais de I00.000 habitantes e concentra ı०\% dos empregos da cidade. E a prefeitura admite não ter um plano de resgate caso outro Sandy aconteça (MCGEEHAN, 20I9). O assentamento original holandês que era positivo devido ao acesso ao mar, tornou-se um problema para os moradores e administradores da cidade.

Junto ao East River, em Downtown Manhattan, localiza-se uma usina de energia. Após o Furacão Sandy, muito se discutiu a cerca do que seria feito com ela, uma vez que a sua explosão resultou na falta de eletricidade por dias. Alguns defendiam que muros altíssimos - ou uma fortaleza - evitariam uma nova entrada de água, enquanto outros acreditavam que a solução seria transferi-la para uma localidade mais distante do mar. As bermas - montes de areia, terra e escombros - podem operar como atenuação ou adaptação: no caso das mais próximas à água, o objetivo é quebrar a força das ondas gigantes, enquanto as mais internas concentram e direcionam o que não foi barrado inicialmente. Neste sentido, faz-se importante levantar a questão acerca de como as cidades poderiam lidar com os possíveis desastres: estariam elas prontas para se proteger ou se adaptar às eventualidades? Teriam elas recursos? Ou quanto tempo levaria para que a paisagem fosse reconstruída? Afinal, ela é fonte de lucro. Sennet (20I8) pondera: equilíbrio estável ou instável? Além dos custos que envolvem esse tipo de segurança serem altos, a tecnologia necessita de mais estudos.

Durante o governo de Rudolph Giuliani ocorreram os atentados às torres do World Trade Center, em II de setembro de 200I. A sua postura, logo após o ataque terrorista, passou segurança aos nova-iorquinos, o que resultou no recebimento do título de Cavaleiro do Império Britânico, que foi entregue pela própria rainha Elizabeth II. O seu discurso ressaltou a importância da união entre os nova-iorquinos, pois eles deveriam sair mais fortes depois da tragédia (SORKIN, 20I8). Entretanto, o alagamento do Memorial construído no local dos escombros durante o Furacão Sandy ressaltou que independente do que seja edificado - seja uma piscina que simboliza o vazio ou o próprio One World, que tem tecnologia construtiva que amortece choques como o de um avião - os moradores da cidade nunca estarão totalmente resguardados (VIEGAS, 2020). 
Por outro lado, existem entidades que se colocam à disposição para a criação de segurança a esses moradores. A Rebuild by Design é uma iniciativa que inspira várias outras pelo mundo e trata de um assunto que diz respeito a milhões de pessoas que terão que sair de suas cidades quando estas forem cobertas pelo mar. No caso nova-iorquino, elaborou-se uma "linha seca" ou Dryline, que contorna a orla de Manhattan. Também foram elaborados projetos para outras áreas afetadas pelo Sandy, como Staten Island (SENNETT, 20I8).

\section{The Big $U$}

Nos Estados Unidos, onde, há muito tempo, a iniciativa e o empreendedorismo cívico são características importantes dos sistemas urbanos, a redução do fluxo dos repasses federais e das receitas dos tributos locais depois de 1972 (ano em que o presidente Nixon declarou o fim da crise urbana, assinalando que o governo federal não tinha mais os recursos fiscais para contribuir com a sua solução) levou ao renascimento do processo de tomada de iniciativas (HARVEY, 2005, p. I66).

As ações sociais e privadas acrescentam e, muitas vezes, lideram os discursos de planejamento urbano. Em 2013, ano seguinte ao Furacão Sandy, a Rebuild by Design, uma iniciativa para a reconstrução das áreas atingidas, junto ao Departamento de Habitação e Desenvolvimento Urbano dos Estados Unidos (HUB), lançou uma competição para projetos na orla de Nova Iorque (REBUILD..., [2OI-]). O furacão havia exposto a vulnerabilidade da cidade e, mesmo que ela estivesse sempre pronta para se reinventar, dessa vez faziam-se necessárias medidas de segurança para os futuros desastres naturais.

Os escritórios BIG - Bjarke Ingels Group (arquitetura e urbanismo), One Architecture (idem), Starr Whitehouse (paisagismo), James Lima Planning + Development (consultoria em mercado imobiliário), além de algumas consultorias na área da construção, se uniram e desenvolveram o The Big U (BIG, 2020). Os nova-iorquinos, assim como depois dos atentados de 9/II, queriam se sentir seguros e que a cidade fosse resiliente. Esse foi o ponto de partida do programa desenvolvido por esses escritórios (VIMEO, 20I5). 
A orla de Lower Manhattan, ou um "grande u" que ela configura, é contornado pelo mar. Desta maneira, as adaptações para tentar garantir a segurança dos moradores podem ser, ao mesmo tempo, um espaço urbano de encontro e sociabilidade, ou até mesmo de atratividade turística. Os idealizadores inclusive sugerem a comparação entre a infraestutura que eles propõem e as grandes obras públicas colocadas em prática por Robert Moses no século 20, e o envolvimento da comunidade no processo de transformação do espaço urbano, assim como defendido por Jane Jacobs. Esse envolvimento configura a prática de participatory design. O BIG, escritório que liderou o projeto, identificou que exemplos já implementados não consideram as futuras expansões das localidades, e como Nova Iorque está em constante modificação e crescimento, torna-se uma grande prioridade em projetos desse porte (BIG, 20I3).

Ao analisar as principais atividades realizadas ao longo da orla, principalmente devido à caracterização de usos dos piers em toda a extensão do Hudson River Park, facilitou-se a adequação do tipo de espaço de convívio para cada localidade (VIEGAS, 2020). Foram desenvolvidos aproximadamente I6 quilômetros de sistema protetor da cidade, que tem o seu início em um edifício residencial também projetado pelo BIG $o$ West 57th (BIG, 2020). O escritório tem algumas marcas no skyline da cidade, o que faz parte do mecanismo que associa starchitects e o branding em torno da paisagem nova-iorquina (VIEGAS, 2020). Assim como esses edifícios de arquitetos com renome caracterizam a nova produção capitalista, o The Big U também configura uma parceria público-privada. Entretanto, Harvey (2005, p. I72) argumenta: “o novo empreendedorismo urbano se apoia na parceria público-privada, enfocando o investimento e o desenvolvimento econômico, por meio da construção especulativa do lugar em vez da melhoria das condições num território específico”. Entretanto, a maior parte dos terrenos está sob controle exclusivamente público (BIG, 2020).

Segundo pesquisas, 220.000 moradores vivem no entorno da área designada ao projeto e o Financial District tem um grande papel na economia mundial. Existem 35.000 unidades de habitação social e, predominantemente perto ao East River (a faixa menos afortunada dos I6 quilômetros), estima-se que 95.000 sejam entre idosos e indivíduos com algum tipo de deficiência locomotiva, além de configurar a região com mais asiáticos e latinos do sul da ilha. Portanto, socialmente, há urgência de proteção e sentimento de segurança, e mesmo que a outras áreas tenham recebido mais capital de investimento (o projeto foi dividido em três regiões principais), o time do 
BIG e a prefeitura de Nova Iorque optaram por começar as obras na orla adjacente ao East River. Focado na comunidade, foram realizados workshops com a população local, houve o diálogo com as organizações e alianças compostas pelas comunidades locais, além de agências federais e conselhos de planejamento urbano. A divisão em três áreas foi essencial para que as necessidades e realidades pontuais fossem analisadas separadamente (BIG, 2020).

Desta maneira, atividades como andar de bicicleta, parar para um lanche, desfrutar de espaços educativos e playground para crianças, praticar caminhadas e outros esportes, foram planejadas para ocorrerem em diversos níveis, de acordo com a configuração original do terreno e as bermas e outros elementos de proteção contra as águas. No processo de participatory design, as principais questões levantadas pelos participantes foram: espaços verdes e de permanência, sentimento de segurança, visibilidade da orla, atividades para a comunidade local e a preferência por bermas largas que pudessem ser ocupadas. Nenhum morador foi a favor de muros que impedissem a vista (BIG, 2020). Em razão do sentimento de pertencimento causado pela paisagem da cidade e do capital simbólico coletivo, a manutenção da imagem faz-se essencial para a cidade como um todo (HARVEY, 2005).

Além disso, sobre a função de parques e praças, Richard Sennett (I976, p. 28) afirma: "é a de mesclar pessoas e diversificar atividades”. Por serem espaços públicos, essas áreas também atuam como espaço de encontro e trocas, de uso e apropriação e da liberdade de expressão, o que caracteriza o espaço de uso coletivo público. Apesar das praças e dos parques simbolizarem o lazer no imaginário comum, também são o palco da dinâmica da vida cotidiana nas cidades, concomitante com a rua. A pluralidade de atividades realizadas em parques abrange desde o passeio despretensioso à prática de atividades físicas e o contato com a natureza, todos estes fundamentais na vida do ser humano. O projeto também propõe que a FDR Drive, uma grande avenida na orla, seja transportada para debaixo das bermas, ou seja, dá preferência às áreas verdes no lugar dos automóveis, o que contradiz com os ideias de Robert Moses para essa região da cidade (BIG, 2020).

Em conjunto com as bermas, serão implementadas barreiras que se fecham no caso de tempestades, o que evita a entrada de água para regiões mais internas da ilha de Manhattan. No inverno, estas também funcionarão como abrigo das intempéries. 
Espaços de convivência que podem ser rapidamente transformados em eventos climáticos também serão implementados abaixo de pontes: sugere-se que feiras locais e espaços para exposição de arte sejam desenvolvidos. No Battery Park as bermas foram projetadas com o intuito de se expandirem em direção ao mar: desta maneira, o contato com a água, por meio de paredes de vidro, criam um novo tipo de interação entre morador, urbe e natureza. Richard Sennet (20I8) argumenta a partir de comentários do climático Klaus Jacob que os idealizadores desse projeto se fixaram na medida de quatro metros e meio para o desenvolvimento das bermas, e que este logo pode ser ineficiente em razão do aumento do nível dos mares. Segundo estudos:

A interação entre a temperatura da água e o desgelo deriva do fato de que este reflete mais energia solar do que aquela: isso isola o sol do mar que está sob o gelo. Quando o gelo derrete, o isolamento diminui ou desaparece e a água do oceano se aquece, o que por sua vez faz mais gelo derreter. Assim começa uma cadeira de água mais quente, gelo que derrete e níveis do oceano em elevação. Hoje, as perdas de gelo dividem-se de forma mais ou menos igual entre a Groenlândia e a Antártida. Se a aceleração atual continuar, o derretimento da cama de gelo poderia contribuir para até 56 centímetros de elevação do nível do mar antes de 2100. (SASSEN, 20I8, p. 242)

Dentre as fragilidades do projeto, tem-se a impossibilidade de atender a todas as demandas levantadas durante os workshops. Apesar de se tratar de um espaço comum a todos, os moradores de uma mesma área percebem-na e interagem com ela de diferentes maneiras. E cada usuário faz o seu próprio recorte da paisagem (BERQUE, I988). Portanto, as prioridades individuais podem muitas vezes não ser atendidas em um projeto com aspectos contidos no participatory design, como o The Big U. A relação entre investidores privados, o setor público, os usuários do espaço e os idealizadores do projeto também complexifica a sua realização. Entre levantar os fundos necessários, fazer o acompanhamento social do projeto e de fato construí-lo, estima-se seis anos (BIG, 2020). O tempo necessário para a realização pode sair caro: tanto pelo volume de mão de obra quanto pela possibilidade de haver outro desastre antes da sua conclusão. Outro problema mencionado pela comunidade refere-se às reformas recentes na orla de Manhattan: o Hudson River Park, o Battery Park e as melhorias no East River, como o South Street Seaport (VIEGAS, 2020). Com a implementação do The Big U, esses projetos teriam os seus investimentos perdidos, uma vez que eles estão na área de intervenção (BIG, 2020). 
Em resumo, as alterações climáticas afetam de diversas formas as cidades litorâneas. Projetos como o The Big $U$ apresentam soluções que podem melhorar a qualidade de vida das populações sujeitas à força da natureza. Entretanto, seja pelo aumento do nível do mar ou pela insurgência de um furacão, os desastres romperão a vida urbana até que medidas mais drásticas sejam tomadas - medidas que levam em consideração todo o contexto da localidade.

\section{Considerações finais}

Os desastres naturais tornaram-se parte da realidade do mundo. A sua frequência aumenta a cada dia, e a destruição da natureza pelo homem constitui a principal causa. No caso do Furacão Sandy, fica claro que a costa leste dos Estados Unidos não estava preparada para a catástrofe, mesmo que seja notória a relação entre a paisagem nova-iorquina e o capital, além de outras relações capitalistas. A indústria imobiliária favorece a manutenção da poluição, seja através do cimento ou da emissão de gases nocivos ao efeito estufa. A vida nas cidades também tem parte na culpa, e sua reprodução não diz respeito à tomada de decisões que levem todos os moradores em consideração.

Entender e planejar as cidades demanda uma compreensão abrangente e complexa sobre todos os fatores que determinam a experiência urbana. No caso deste artigo, os desastres naturais causados pela água tornam-se centrais à discussão, uma vez que sem a ajuda de especialistas e moradores locais, as transformações urbanas não serão capazes de apaziguar de forma justa a resposta da natureza ao desenvolvimento das cidades. A gestão de caráter empresarial não permite que as infraestruturas cheguem de forma igual a todos os moradores, entretanto, a dinâmica socioeconômica da cidade dependente de todos para o seu funcionamento.

Assim como em vários outros aspectos do capitalismo, as incoerências configuram, ao mesmo tempo, a base da sua manutenção e a possibilidade, neste caso, de se evitar expulsões futuras. As novas topografias e estratégias de segurança sugeridas para os desastres ambientais das cidades, portanto, devem ser acessíveis a todos, sem exceção. Até isso acontecer, cresce o desejo da materialização da equidade na esfera urbana por meio do planejamento e conta-se com as iniciativas sociais que se preocupam tanto com as pessoas quanto com o meio ambiente. 


\section{Referências}

ASSUNTO, Rosario. A paisagem e a estética. In: SERRÃO, Adriana V. (Coord). Filosofia da paisagem: uma antologia. 2. ed. Lisboa: Centro de Filosofia da Universidade de Lisboa, 2013, p. 339-376.

BEISER, Vince. Blockbuster: Without concrete, our civilization would be nowhere. With concrete, the planet is suffering. Some clever chemistry can help cure that problem. Wired, New York, v. 28, n. 4, abril 2020. Capture, edição digital.

BERQUE, Augustin. Paisagem-marca, paisagem-matriz: elementos da problemática para uma geografia cultural. In: CORREAA, Roberto Lobato; ROSENDAHL, Zeny (Eds.). Paisagem, tempo e cultura. Rio de Janeiro: EdUERJ, I998 [I984], p. 84-9I.

BIG. The Big U: Promoting resilience post-Sandy through innovative planning, design, \& programming. Bjarke Ingels Group, New York, 20I3. Disponível em: http://www.rebuildbydesign.org/data/files/675.pdf. Acesso em: 20 abr. 2020.

CARO, Robert A. The power broker: Robert Moses and the fall of New York. New York: Vintage Books, I975.

CITY OF NEW YORK. Hurricane Sandy. New York, 2020. Disponível em: https:// wwwi.nyc.gov/site/cdbgdr/about/About\%20Hurricane\%20Sandy.page. Acesso em: o6 maio 2020 .

FLAVELLE, Christopher; SCHWARTZ, John. Cities are flouting flood rules. The cost: \$I billion. The New York Times, New York, ano I69, 9 abr. 2020. Climate. Disponível em: https://www.nytimes.com/2020/04/09/climate/fema-floodinsurance.html. Acesso em: 06 maio 2020.

HARVEY, David. A produção capitalista do espaço. Tradução de Carlos Szlak. São Paulo: Annablume, 2005. Título original: Spaces of capital: Towards a critical geography. 
HOMBERGER, Eric. The historical atlas of New York City: a visual celebration of 400 years of New York City's history. New York: Holt Paperbacks, I998.

JACOBS, Jane. The death and life of great American cities. New York: Vintage Books, I992.

MCGEEHAN, Patrick. 6 Years After Hurricane Sandy, here's what they came up with: really big sandbags - City officials will install the sandbags as the first line of defense against storm surges in part of Lower Manhattan. The New York Times, New York, ano I68, 5 maio 20I9. Climate. Disponível em: https://www.nytimes. com/2019/05/05/nyregion/hurricane-sandy-manhattan-flooding.html. Acesso em: 06 maio 2020.

REBUILD BY DESIGN. The Big U. [20I-]. Disponível em: http://www. rebuildbydesign.org/our-work/all-proposals/winning-projects/big-u. Acesso em: II maio 2020.

SASSEN, Saskia. Expulsões: brutalidade e complexidade na economia global. Tradução de Angélica Freitas. São Paulo: Paz e Terra, 20ı6. Título original: Cities at War - Global Insecurity And Urban Resistance.

SENNETT, Richard. Construir e habitar: ética para uma cidade aberta. Tradução de Clóvis Marques. Rio de Janeiro: Editora Record, 20I8. Título original: Building and Dwelling: ethics.

SENNETT, Richard. O declínio do homem público: as tiranias da intimidade. Tradução de Lygia de Araújo Watanabe. Rio de Janeiro: Editora Record, I976. Título original: The Fall of Public Man.

SIMMEL, Georg. A filosofia da paisagem. In: SERRÃO, Adriana V. (Coord). Filosofia da paisagem: uma antologia. 2. ed. Lisboa: Centro de Filosofia da Universidade de Lisboa, 2013, p 39-5I.

SORKIN, Michael. Twenty minutes in Manhattan. New York: North Point Press, 2013. 
SORKIN, Michael. What goes up: the right and wrongs to the city. New York: Verso, 2018.

VIEGAS, Marina Vale. Paisagem latente em Nova Iorque: novas incursões no urbanismo. Belo Horizonte: Páginas Editora, 2020.

VIMEO. THE BIG U - BIG teams vision for Rebuild by Design. Produção: BIG Bjarke Ingels Group. Disponível em: https://vimeo.com/II7303273. Acesso em: II maio 2020 .

ZUKIN, Sharon. Naked city: the death and life of authentic urban places. New York: Oxford University Press, 20II. 